\title{
Secondhand Smoke Exposure among Nonsmokers in China
}

\author{
Lin Xiao $^{1 *}$, Yuan Jiang ${ }^{1}$, Jingru Zhang ${ }^{2}$, Mark Parascandola ${ }^{3}$
}

\begin{abstract}
Background: China signed the World Health Organization Framework Convention on Tobacco Control and conducted a series of activities to protect people from secondhand smoke exposure. This paper explores the changes in prevalence of secondhand smoke exposure among nonsmokers between 2010 and 2015. Methods: Data from the 2010 Global Adult Tobacco Survey and 2015 National Adult Tobacco Survey were used in this study. Due to the complex sample design for these surveys, data were weighted and analyzed using the SAS 9.3 complex survey data analysis procedure. The Chi-square test was used for comparison among different groups. Results: From 2010 to 2015, secondhand smoke exposure among nonsmokers decreased in restaurants, government buildings, health-care facilities, schools, and public transportation in China $(\mathrm{p}<0.05)$. The relative change was most significant for schools $(52.1 \%)$, followed by public transportation $(49.4 \%)$ and government buildings $(42.2 \%)$. The percentage of secondhand smoke exposure reported in workplaces declined from $55.2 \%$ to $45.3 \%$. Secondhand smoke exposure at home reduced from $58.3 \%$ to $46.7 \%$. People's awareness that secondhand smoke could cause heart disease in adults, lung illness in children, and lung cancer in adults increased from $24.6 \%$ to $36.0 \%$. Additionally, support for smoke-free policies is high among the Chinese population. Even for restaurants, where support for smoke-free policies was lowest, $75.1 \%$ of nonsmokers and 55.3\% of smokers supported smoke-free policies. Conclusion: Secondhand smoke exposure declined from 2010 to 2015 in China but remains a serious problem. Public awareness about the hazards of secondhand smoke is increasing and Chinese people support smoke-free laws.
\end{abstract}

Keywords: Secondhand smoke- surveillance and monitoring- smoke-free policy

Asian Pac J Cancer Prev, 21, Progress of Tobacco Control in the Western Pacific Region Suppl, 17-22

\section{Introduction}

Tobacco use kills approximately 7 million people globally every year and is a significant threat to health and development (World Health Organization, 2017). China is the largest consumer of tobacco in the world. There are 316 million smokers and about $44 \%$ of the cigarettes consumed globally are smoked in China (Chinese Center for Disease Control and Prevention, 2016; Michael et al., 2015). Consequently, more than 1 million Chinese die of tobacco-related diseases each year and secondhand smoke exposure remains a serious public health problem (Ministry of Health, 2012).

China has taken a number of steps to prevent people from exposure to secondhand smoke. An important step was banning smoking in health facilities by the Ministry of Health in 2009 (Ministry of Health, 2009), followed by the Ministry of Education banning smoking in primary schools and middle schools in 2010 (Ministry of Education, 2010). In recent years, there have been national and local mass media campaigns to raise awareness about the risks of secondhand smoke and many restaurants and private companies have implemented their own smoke-free policies (Redmon et al., 2014). In 2013, the General Office of the Communist Party of China Central Committee and the General Office of the State Council issued a notice requiring leading officials to set an example through their own actions, by avoiding tobacco use in public places and supporting the implementation of smoke-free policies (The State Council of the People's Republic of China, 2013). In 2014, smoking was banned in high-speed trains (The State Council of the People's Republic of China, 2014). "No smoking in public places" was included in China's $12^{\text {th }}$ and $13^{\text {th }}$ Five-Year Plans (The National People's Congress of the People's Republic of China, 2011; The State Council of the People's Republic of China, 2017), and passed at the National People's Congress conferences in 2011 and 2016, respectively. Local smoke-free ordinances were enacted in 18 cities, including Beijing and Shanghai. Following this, in 2014, the Legislation Office of the State Council embarked on drafting the first nationwide regulation to ban smoking in indoor public places (Legislation Office of the State Council, 2014; National Health and Family Planning Committee, 2014).

This study explores the changes in prevalence of secondhand smoke exposure among nonsmokers in public places, workplaces, public transportation, and homes, as well as people's knowledge and perceptions about

${ }^{1}$ Tobacco Control Office, Chinese Center for Disease Control and Prevention, Beijing, China. ${ }^{2}$ School of Public Health, Peking University, China. ${ }^{3}$ National Cancer Institute, USA. *For Correspondence: xiaolin@chinacdc.cn. 
secondhand smoke from 2010 to 2015 in China.

\section{Materials and Methods}

\section{Data resource}

The 2010 Global Adult Tobacco Survey in China and 2015 National Adult Tobacco Survey were nationally representative household surveys conducted by the Chinese Center for Disease Control and Prevention (Tobacco Control Office, Chinese Center for Disease Control and Prevention, 2011; Chinese Center for Disease Control and Prevention, 2016). The target population of the two surveys were non-institutionalized men and women aged 15 and older. The survey questionnaire collected information on demographics; tobacco use; cessation; secondhand smoke exposure; media exposure; and knowledge, attitudes, and perceptions about tobacco use and tobacco control measures. Handheld computers were used to collect data. The key indicators used in this study were measured using the same questions for both surveys.

\section{Outcome variables}

Outcome variables used were secondhand smoke exposure among nonsmokers in public places (yes/no), secondhand smoke exposure among nonsmokers at workplaces (yes/no); secondhand smoke exposure among nonsmokers at home (yes/no); knowledge that exposure to secondhand smoke causes heart disease in adults, lung illness in children, lung cancer in adults, and all three diseases (yes/no/don't know); and people's attitude toward smoke-free policy in various public places (support or not). Restaurants, government buildings, health-care facilities, schools, and public transportation were included in public places. Nonsmoker status was determined by the question: "Do you currently smoke tobacco on a daily basis, less than daily, or not at all?" Respondents who answered "not at all" were considered nonsmokers.

The questionnaire did not include a direct measure of secondhand smoke exposure among respondents. Instead, two questions were used to provide an indirect measure of change in prevalence of secondhand smoke in certain public places between 2010 and 2015. For example, respondents were asked: "During the past 30 days, did you visit any government buildings or government offices?" Those who answered "yes" were asked: "Did anyone smoke inside of these government buildings or government offices that you visited in the past 30 days?" Therefore, secondhand smoke exposure in public places was measured by whether respondents who had visited these public places in the past 30 days noticed anyone smoking there. The question about secondhand smoke exposure at workplaces included respondents aged 16 to 60 who had noticed anyone smoke at a workplace. Respondents who reported any frequency of smoking at home (daily, weekly, monthly, or less than monthly) were considered to be exposed to secondhand smoke in the home.

\section{Independent variables}

Independent variables used were gender (male/female), age, education level, resident (urban/rural), and occupation. The age groups in this study were classified into 15-24, 25-34, 35-44, 45-54, and 55+ years old. Education levels included four categories: primary school or less, attended secondary school, high school, and college graduate or above. Occupations were categorized into agriculture worker, business or service employee, medical/health personnel, teaching staff, and others (see Table 1).

\section{Statistical analysis}

Due to the complex survey sample design for these surveys, each responding unit was assigned a unique survey weight that was used to produce estimates of population parameters. All computations were performed using the SAS 9.3 complex survey data analysis procedure. Percentage or proportion was used for descriptive statistics. The Chi-square test was used for comparison among different groups. A p value $<0.05$ was considered statistically significant.

\section{Results}

Secondhand smoke exposure among nonsmokers in public places

In 2015, exposure to secondhand smoke among nonsmokers was most commonly reported in restaurants (70.1\%). The proportion of nonsmokers exposed to secondhand smoke in other public places included: $32.0 \%$ in government buildings, $24.2 \%$ in health-care facilities, $17.1 \%$ in schools, and $16.1 \%$ on public transportation. Secondhand smoke exposure was higher among male than female nonsmokers in restaurants, government buildings, and schools $(\mathrm{p}<0.05)$. There was no difference between genders in health-care facilities and public transportation. The proportion of people exposed to secondhand smoke in schools was greatest for the 15-24 age group (29.8\%) compared with other age groups $(\mathrm{p}<0.05)$.

Between 2010 and 2015, the proportion of respondents reporting secondhand smoke exposure dropped in all categories of public places $(\mathrm{p}<0.05)$. The relative change was most significant for schools $(52.1 \%)$, followed by public transportation (49.4\%) and government buildings (42.2\%) (see Figure 1).

\section{Secondhand smoke exposure among nonsmokers at workplaces}

In 2015 , the percentage of nonsmokers working in indoor locations exposed to secondhand smoke at work during the last 30 days was $45.3 \%$ (54.6\% for males and $39.8 \%$ for females). The proportion increased with age $(p<0.001)$ and declined with higher education levels (i.e., college or above) $(p<0.001)$. There was no significant difference between urban and rural areas $(p=0.757)$. By occupational category, the highest proportion of people exposed to secondhand smoke was agriculture workers (68.5\%), followed by business or service employees $(49.7 \%)$, while the proportion among medical/health personnel and teaching staff were $23.7 \%$ and $30.2 \%$, respectively.

From 2010 to 2015, the percentage of secondhand smoke exposure in the workplace declined by $9.9 \%$. The 
Table 1. Percentage of Nonsmokers $\geq 15$ Years Old Exposed to Secondhand Smoke in the Workplace*

\begin{tabular}{|c|c|c|c|c|}
\hline & \multicolumn{2}{|c|}{2010} & \multicolumn{2}{|c|}{2015} \\
\hline & $\%$ & $95 \% \mathrm{CI}$ & $\%$ & $95 \% \mathrm{CI}$ \\
\hline Overall & 55.2 & $50.4 \sim 59.9$ & 45.3 & $41.4 \sim 49.2$ \\
\hline \multicolumn{5}{|l|}{ Gender } \\
\hline Male & 58 & $51.9 \sim 63.8$ & 54.6 & $48.7 \sim 60.4$ \\
\hline Female & 53.3 & $47.6 \sim 58.9$ & 39.8 & $35.9 \sim 43.9$ \\
\hline \multicolumn{5}{|l|}{ Age (years) } \\
\hline $15-24$ & 44.6 & $38.1 \sim 51.2$ & 34.1 & $27.2 \sim 41.7$ \\
\hline $25-34$ & 55.1 & $48.0 \sim 62.0$ & 42.7 & $38.2 \sim 47.3$ \\
\hline $35-44$ & 62.1 & $54.9 \sim 68.7$ & 52.2 & $46.1 \sim 58.2$ \\
\hline $45-54$ & 66.5 & $57.2 \sim 74.7$ & 54.4 & $48.1 \sim 60.6$ \\
\hline $55-60$ & 67.7 & $56.8 \sim 77.0$ & 60.7 & $48.2 \sim 71.9$ \\
\hline \multicolumn{5}{|l|}{ Education level } \\
\hline Primary school or less & 67.4 & $52.8 \sim 79.3$ & 55.2 & $45.5 \sim 64.4$ \\
\hline Attended secondary school & 64.7 & $58.0 \sim 70.9$ & 57.9 & $50.7 \sim 64.8$ \\
\hline High school & 59 & $50.7 \sim 66.9$ & 49.2 & $43.2 \sim 55.3$ \\
\hline College graduate or above & 57 & $48.6 \sim 64.9$ & 42.5 & $37.0 \sim 48.2$ \\
\hline \multicolumn{5}{|l|}{ Resident } \\
\hline Urban & 53.7 & $47.6 \sim 59.7$ & 44.9 & $40.4 \sim 49.5$ \\
\hline Rural & 57.9 & $52.0 \sim 63.6$ & 46.3 & $38.8 \sim 53.9$ \\
\hline \multicolumn{5}{|l|}{ Occupation } \\
\hline Agriculture worker & 73.1 & $56.6 \sim 85.0$ & 68.5 & $48.2 \sim 83.6$ \\
\hline Business or service employee & 60.2 & $53.5 \sim 66.6$ & 49.7 & $45.0 \sim 54.5$ \\
\hline Medical/health personnel & 51.1 & $37.4 \sim 64.6$ & 23.7 & $15.6 \sim 34.4$ \\
\hline Teaching staff & 49.2 & $38.1 \sim 60.3$ & 30.2 & $20.5 \sim 42.1$ \\
\hline Others & 49.2 & $43.9 \sim 54.4$ & 37.2 & $30.5 \sim 44.4$ \\
\hline
\end{tabular}

Note: Secondhand smoke exposure in the workplace is calculated only among respondents 16-60 years old; Data sources: 2010 Global Adult Tobacco Survey (GATS) and 2015 National Adult Tobacco Survey (NATS).

proportion dropped more among women (13.5\%) than among men (3.4\%). By education level, the change was greatest among those with a college education or above - a decrease from $57.0 \%$ in 2010 to $42.5 \%$ in 2015 . By occupational category, the largest changes in exposure were among medical/health personnel and teaching staff, with a decrease from $51.1 \%$ to $23.7 \%$ among medical/
Secondhand Smoke Exposure among Nonsmokers in China

health personnel $(\mathrm{p}=0.017)$ and $49.2 \%$ to $30.2 \%$ among teaching staff $(\mathrm{p}<0.001)$ (see Table 1$)$.

Secondhand smoke exposure among nonsmokers at home

In 2015, 46.7\% of nonsmokers were exposed to secondhand smoke at home. The proportion was higher in rural areas (57.5\%) compared with urban areas (36.9\%) $(\mathrm{p}<0.001)$. Secondhand smoke exposure at home differed dramatically among groups with different education levels $(\mathrm{p}<0.001)$. Exposure was much lower among those with a university education or above $(23.5 \%)$ compared to those with only a secondary school education $(50.9 \%)$ or primary school education or less $(50.5 \%)$.

From 2010 to 2015, the percentage of reported secondhand smoke at home dropped from $58.3 \%$ to $46.7 \%$ ( $\mathrm{p}<0.001$ ). It declined from $48.4 \%$ to $37.4 \%$ among males and from $63.2 \%$ to $51.4 \%$ among females. The relative change was much more significant in urban areas (13.4\%) than in rural areas $(7.7 \%)$ and was greatest among those with a university education or above $(44.0 \%)$ compared to those with lower education levels.

\section{Awareness of the hazards of secondhand smoke}

In 2015, the percentage of adults who knew that secondhand smoke causes heart disease in adults, lung illness in children, or lung cancer in adults was $41.7 \%$, $65.2 \%$, and $64.6 \%$, respectively, while $36.0 \%$ of adults were aware that secondhand smoke could cause all three diseases. Rural residents had a lower awareness of the health hazards posed by secondhand smoke (27.0\%) compared with urban residents $(44.7 \%)$. Awareness of the health hazards posed by secondhand smoke was closely related to education level $(\mathrm{p}<0.01)$. Only $16.4 \%$ of those with an education level of primary school or less were aware that secondhand smoke could cause all three diseases. The proportion among those with an education level of college or above was $54.9 \%$. Although people's awareness of secondhand smoke hazards is still low, it increased substantially from 2010 to 2015, as shown in Figure 2.

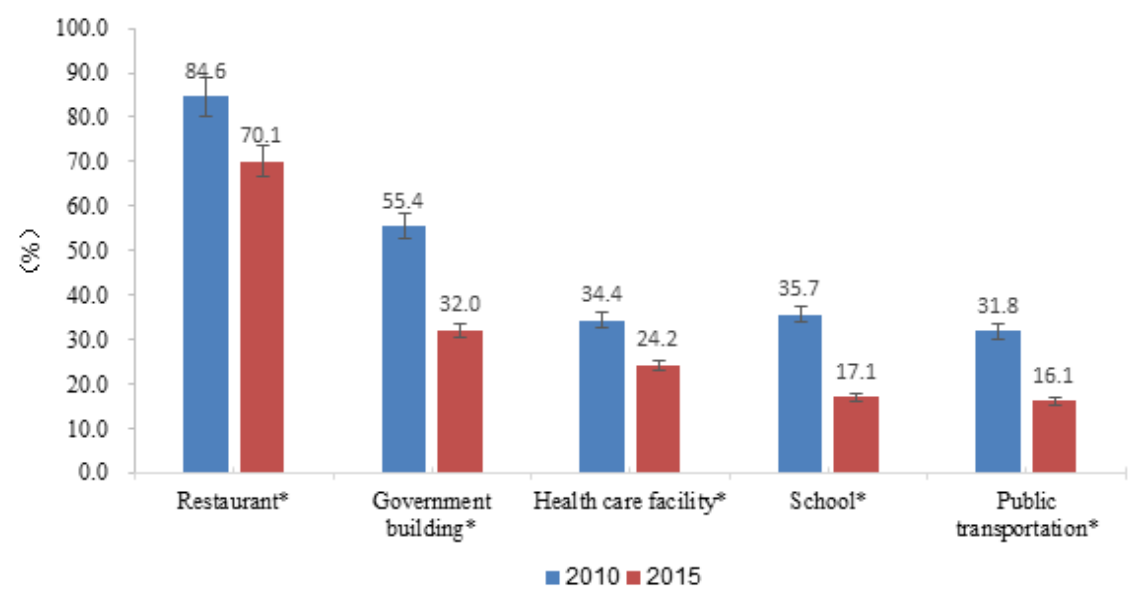

Figure 1. Percentage of Nonsmokers $\geq 15$ Years Old Exposed to Secondhand Smoke at Public Places, 2010 and 2015. Note, * P $<0.05$; Data sources, 2010 Global Adult Tobacco Survey (GATS) and 2015 National Adult Tobacco Survey (NATS). 
Table 2. People's Support towards Smoke-Free Policies in Public Places in 2015

\begin{tabular}{lcccccc}
\hline & \multicolumn{2}{c}{ Nonsmoker } & \multicolumn{2}{c}{ Smoker } & Chi-square & $P$-value \\
& $\%$ & $95 \% \mathrm{CI}$ & $\%$ & $95 \% \mathrm{CI}$ & & \\
\hline Health-care facility & 94.7 & $93.5 \sim 95.6$ & 93.8 & $92.3 \sim 94.9$ & 4.74 & 0.18 \\
Workplace & 88.2 & $85.9 \sim 90.1$ & 80.9 & $77.6 \sim 83.8$ & 133.834 & $<0.001$ \\
Restaurant & 75.1 & $71.9 \sim 78.0$ & 55.3 & $51.5 \sim 59.0$ & 558.902 & $<0.001$ \\
University & 86.9 & $84.2 \sim 89.1$ & 82.6 & $79.7 \sim 85.2$ & 44.877 & $<0.001$ \\
Taxi & 87.2 & $84.5 \sim 89.5$ & 79 & $76.0 \sim 81.7$ & 160.44 & $<0.001$ \\
Primary and secondary school & 93.4 & $91.6 \sim 94.8$ & 92 & $90.3 \sim 93.5$ & 7.942 & 0.069 \\
\hline
\end{tabular}

Data source, 2015 National Adult Tobacco Survey (NATS).

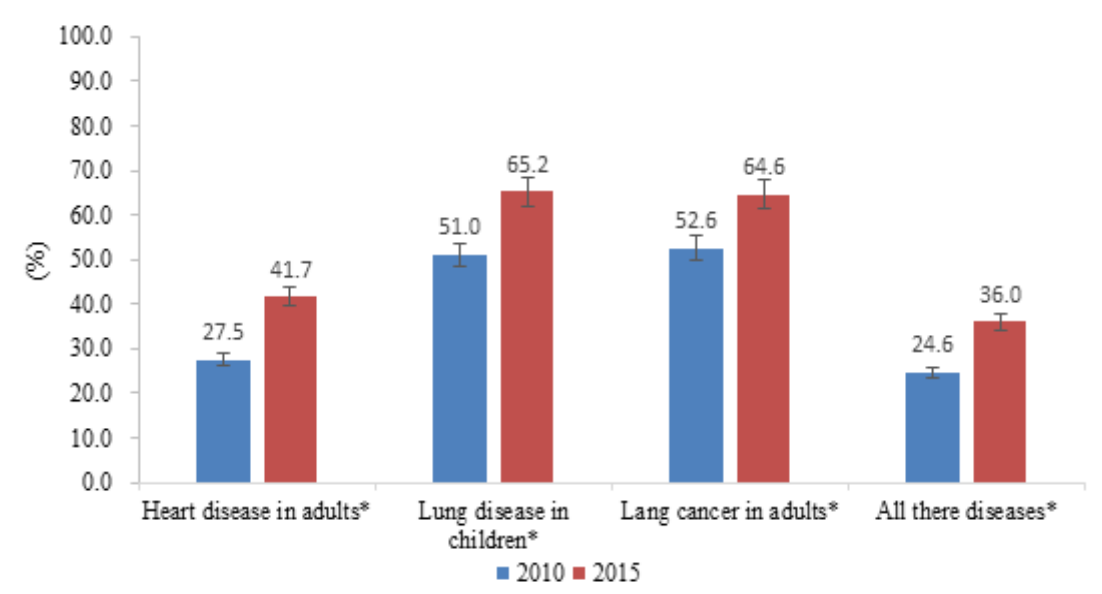

Figure 2. Peoples Awareness of Hazard of Secondhand Smoke , 2010-2015

Public support for smoke-free law

In 2015, more than $90 \%$ of respondents (both nonsmokers and smokers) supported banning smoking in indoor spaces at health-care facilities, primary schools, and secondary schools. In terms of smoke-free policies in other public places, nonsmokers were more likely than smokers to support smoke-free policies (although support among both groups was substantial). This included support for smoke-free policies in the workplace $(88.2 \%$ nonsmokers vs. $80.9 \%$ smokers), universities ( $86.9 \%$ vs. $82.6 \%$ ), restaurants $75.1 \%$ vs. $55.3 \%$ ), and taxis $(87.2 \%$ vs. 79.0\%) (see Table 2).

\section{Discussion}

From 2010 to 2015, nonsmokers' exposure to secondhand smoke in public places and workplaces in China declined significantly $(\mathrm{p}<0.001)$. Despite this reduction, exposure to secondhand smoke remained high in 2015 , with exposure at $70.1 \%$ in restaurants and $45.3 \%$ in workplaces. These levels are much higher than what has been observed in many other countries (Ministry of Health and Social Development of the Russian Federation, 2017; Pan American Health Organization, INDC Brazil, 2010; Bureau of Tobacco Control, Department of Disease Control (DDC) Ministry of Public Health, 2011). It indicates that secondhand smoke exposure is still a serious public health problem in China.

Starting in 2009, the Chinese Ministry of Health and Ministry of Education implemented regulations to prohibit smoking inside health-care facilities and on primary and secondary school campuses. Consequently, secondhand smoke exposure in those places was already relatively low in 2010 and declined between 2010 and 2015 . Additionally, the proportion of medical/health personnel and teaching staff exposed to secondhand smoke at their workplaces decreased more than for other occupations between the two survey years. Moreover, while 55.4\% of nonsmokers were exposed to secondhand smoke in government buildings in 2010 (before the 2013 notice requiring government offices to go smoke-free), this number declined to $32.0 \%$ in 2015 . These findings provide support for the conclusion that targeted smoke-free environment campaigns are effective. The lowest level of secondhand smoke exposure observed was in public transportation. This is likely due to the fact that smokefree laws and regulations for public transportation were enacted in 1997 (Civil Aviation Administration of China, 2015). This, in addition to the prohibition of smoking on high-speed trains in 2014 (Civil Aviation Administration of China, 2014), contributed to a further reduction in secondhand smoke exposure on public transportation. This suggests that smoke-free laws or regulations, as shown in the case for the public transportation regulations, are more efficient than a smoke-free campaign alone.

A substantial body of evidence from many countries has shown that comprehensive smoke-free laws can reduce secondhand smoke exposure and improve the air quality of indoor places (Fong et al., 2013; Mulcahy et al., 2005; Hyland et al., 2008). Additionally, in cities in China that have implemented comprehensive smoke-free laws, such as Beijing, secondhand smoke exposure has 
decreased much more than at the national level (Xiao et al., 2016). This highlights the need for a comprehensive national smoke-free law to ensure the greatest impact on reducing secondhand smoke exposure in China. Given President Xi Jinping's pronouncement that "An all-around moderately prosperous society cannot be achieved without the people's all-around health," in addition to the "Healthy China" development strategy, a national comprehensive smoke-free law should be enacted for China to protect people from secondhand smoke and its impact on public health.

The results of this paper indicate that there is broad support for smoke-free policies among the Chinese population. The findings of this study show that people are aware that secondhand smoke can cause heart disease in adults, lung illness in children, and lung cancer in adults. Furthermore, smoking in the home declined substantially over the five-year period between 2010 and 2015, especially for those with higher education. This indicates that Chinese people are increasingly aware of the hazards of secondhand smoke and are beginning to take steps to protect themselves and the next generation. In addition, this study found smokers as well as nonsmokers to be in support of smoke-free policies. This demonstrates that a national comprehensive smoke-free law would be welcome in China.

\section{Acknowledgements}

This study was supported by the National Health and Family Planning Commission of China, World Health Organization Regional Office for the Western Pacific, and U.S. Centers for Disease Control and Prevention. The authors would like to acknowledge local representatives of the Centers for Disease Control and Prevention and Centers for Health Education for their contribution in data collection.

\section{Conflict of Interest Statement}

The authors have no conflicts of interest associated with the material presented in this paper. The ORCID of the corresponding author is 0000-0002-5052-6663.

\section{References}

Bureau of Tobacco Control, Department of Disease Control (DDC) Ministry of Public Health (2011). Global adult tobacco survey: Thailand report 2011[cited 2020 Oct 20]. Available from: http://www.who.int/tobacco/surveillance/ survey/gats/thailand_report_2011.pdf?ua=1.

Chinese Center for Disease Control and Prevention (2016). The 2015 China Adult Tobacco Survey. Beijing: People's Medical Publishing House, pp 10 (Chinese).

Chinese Center for Disease Control and Prevention (2016) The 2015 China Adult Tobacco Survey. Beijing: People's Medical Publishing House (Chinese).

Civil Aviation Administration of China (2015). No smoking regulations in civil airports and civil aircraft [cited 2020 Jan 20]. Available from: http://www.caac.gov.cn/XXGK/ XXGK/MHGZ/ 201511/t20151102 8550.html (Chinese).

Fong GT, Craig LV, Guignard R, et al (2013). Evaluating the effectiveness of France's indoor smoke-free law 1 year and
Secondhand Smoke Exposure among Nonsmokers in China

5 years after implementation: Findings from the ITC France Survey. PLoS One, 8, e66692.

Hyland A, Travers MJ, Dresler C, Higbee1 C, Cummings KM (2008). A 32-country comparison of tobacco smoke derived particle levels in indoor public places. Tob Control, 17, 159-65.

Legislation Office of the State Council (2014). The notice to hear public opinion and comments on the regulation on control smoking in public places (draft) [cited 2020 Jan 20]. Available from:http://www.nhfpc.gov.cn/zhuzhan/zqyj/201 411/16b813422bae4cfd93823102ee45b7f3.shtml (Chinese).

Michael E, Judith M, Neil S, et al (2015). The Tobacco Atlas. Atlanta: The American Cancer Society, pp 30-1.

Ministry of Education (2010). Opinion on further strengthens tobacco control in Schools [cited 2020 Jan 20]. Available from:http://www.moe.gov.cn/srcsite/A17/moe_943/ moe 946/201007/t20 100713 92850.html (Chinese).

Ministry of Health (2009). Decision on banning smoking in health facilitates from 2011[cited $2020 \mathrm{Jn}$ 20]. Available from: http://www.gov.cn/zwgk/2009-05/22/content_1321944. htm (Chinese).

Ministry of Health (2012). China Report on the Health Hazards of Smoking. Beijing: People's medical publishing house, pp 9 (Chinese).

Ministry of Health and Social Development of the Russian Federation (2017). Global Adult Tobacco Survey (GATS) Russian Federation 2009 Country Report [cited 2020 Jan 20]. Available from: http://www.who.int/tobacco/surveillance/ ru_tfi_gatsrussian_countryreport.pdf.

Mulcahy M, Evans DS, Hammond SK, Repace JL, Byrne M (2005). Secondhand smoke exposure and risk following the Irish smoking ban: an assessment of salivary cotinine concentrations in hotel workers and air nicotine levels in bars. Tob Control, 14, 384-8.

National Health and Family Planning Committee (2014). The first nationwide regulation of smoking ban in public spaces (draft) [cited 2020 Jan 20]. Available from: http://www.nhfpc.gov.cn/ zhuzhan/zcjd/201411/ cc090d9b0be641ac942daflb101982b4.shtml (Chinese).

Pan American Health Organization, INDC Brazil (2010). Global Adult Tobacco Survey Brazil Report [cited 2020 Jan 20]. Available from: http://www1.paho.org/hq/dmdocuments /2010/GATS-2010-Brazil-Report-en.pdf.

Redmon P, Koplan J, Eriksen M, Shuyang L, Kean W (2014). The Role of Cities in Reducing Smoking in China. Int $J$ Environ Res Public Health, 11, 10062-75.

The National People's Congress of the People's Republic of China (2011). The Twelfth Five-Year Plan for National Economic and Social Development of the People's Republic of China[cited 2020 Jan 20].Available from: http://www.gov. $\mathrm{cn} / 2011 \mathrm{lh} /$ content 1825838.htm (Chinese).

The State Council of the People's Republic of China (2013). Notice on Leaders' Lead to Preventing Smoking in Public Places [cited 2020 Jan 20]. Available from: http://www.gov. cn/zheng ce/2013-12/29/content_2640100.htm (Chinese).

The State Council of the People's Republic of China (2014). Regulations on Railway Safety Management [cited 2020 Jan 20]. Available from: http://www.gov.cn/fffg/2013-09/06/ content 2482653.htm (Chinese).

The State Council of the People's Republic of China (2017). The 13th Health Development 5-year Plan [cited 2020 Jan 20]. Available from: http://www.gov.cn/zhengce/ content/2017-01/10/co ntent_5158488.htm (Chinese).

Tobacco Control Office, Chinese Center for Disease Control and Prevention (2011). Global Adult Tobacco Survey (GATS) China 2010 Country Report. Beijing: China Three Gorges Publishing House (Chinese). 
Lin Xiao et al

World Health Organization (2017). WHO report on the global tobacco epidemic, 2017-Monitoring tobacco use and prevention policies. Geneva: World Health Organization, pp 24.

Xiao L, Jiang Y, Liu XR, et al. (2016). Smoking reduced in urban restaurants: the effect of Beijing Smoking Control Regulation. Tob Control, 26, e75-8.

\section{c) (i) (8)}

This work is licensed under a Creative Commons AttributionNon Commercial 4.0 International License. 